\title{
Mexican culture collection CINVESTAV-México, importance, functions and services
}

\begin{abstract}
The Mexican Culture Collection of Microorganismsis recognized as biological resource center (BRC) by CONABIO (Comisión Nacional para el Conocimiento y Uso de la Biodiversidad, México); member of WFCC since 1974 under acronym CDBB-500, maintains and studies a group of microorganism as bacteria, actinomycetes, filamentous fungi, yeasts and microalgae in order to provide a variety of support services for basic and applied research on microbiology in México.
\end{abstract}

Keywords: culture collection, preservation, databases
Volume 4 Issue 4 - 2020

\author{
Estrada-Mora Juan C, Estrada-Bárcenas \\ Daniel \\ Mexican Culture Collection, Research and Advanced Studies \\ Center of the National Polytechnic Institute (CINVESTAV-IPN), \\ México
}

Correspondence: Estrada-Mora Juan C, Mexican Culture Collection, CINVESTAVIPN. Av. IPN 2508, San Pedro Zacatenco, México, D.F. C.P. 07360. Tel 52-5557473903,

Email jestrada@cinvestav.mx

Received: July 27, 2020 | Published: August 10, 2020
Abbreviations: $\mathrm{BRC}$, biological resource center; $\mathrm{CDBB}$, collection of the bioengineering biotechnology department; CINVESTAV, center for research and advanced studies of the national polytechnic institute; WDCM, world data center for microorganisms; WFCC, world federation for culture collections; OECD, organization for economic cooperation and development; NAFTA, north American free trade agreement; CONABIO, national commission for the use and knowledge of biodiversity; IMPI, mexican institute of intellectual property

\section{Introduction}

Microbial culture collections are entities where a series of activities are carried out, whose fundamental objective is to obtain, preserve, classify, study and record, in a complete and accessible manner, a collection of authentically pure microbial cultures, of specific interest and available on demand, being a decisive factor in the development of microbiology in any of its branches and applications. ${ }^{1-5}$

Based on the above concepts, as a result of Department of Biotechnology and Bioengineering foundation CINVESTAV-IPN, was needing to integrate a collection of microorganisms to assist in the teaching and research activities of the department.

However, there quirements of other national and international institutions at originated a major development than planned for the collection, this functions and services made it worthy to be recognized under international acronym of culture collections WDCM based on the OECD guidelines for Biological Resource Centres. ${ }^{1,2}$

At present, the Mexican Culture Collection of CINVESTAV is part of the National Laboratory of Experimental Services, to provide services and support to the research centers as well as the commercial sector, this laboratory has a web page that can be consulted through (the site http://cdbb.cinvestav.mx/cdbb/index.html.)

Not only preservation of microorganisms, a relevant service provided by the CINVESTAV's collection is the custody of strains, in order to protect the viability and stability of their properties, collection can to guarantee confidentiality on the application or use of the deposited cultures, mainly production cultures coming from the industrial sector, research or genetically manipulated, as application of patents or other particular interest. ${ }^{2,3}$

Since establishment of the collection at date, many research Works have been done about influence of physicochemical parameters on efficiency of conservation methods. CDBB-500 have been support to supply and safe deposit of strains for more than 400 national and foreign institutions.

Members of culture collections have participated in many of refresher courses, congresses, symposia, workshops and have organized national and international courses related to the subject of microorganism collections.

As a result of signing of NAFTA with the United States of America and Canada, CONABIO have selected the Culture collection from CINVESTAV-IPN as National Reference Center, to be recognized as international authority in strain deposit. To date, there are production strains from several important companies in the country that have been protected by safe deposit; cell lines and other microorganisms involved in biotechnological processes have been incorporated. Their deposit in the collection is of main importance for the development of patents before the IMPI, to obtain profits from the explitation within the country for the benefit of their explitation holders.

CINVESTAV collection has participated in edition of laboratory manuals, book chapters in microbiology field. Now have a data base to be accession line to consult by scientifc community. Recently, a book "Memoria de la Base de Data from the Colección Nacional Microbiana CDBB-500", was edited by Porrúa Print, Mexico (May 2012), ISBN 03-2012-051611405100-01, this is a retrospective of microbiological work and information management related to the computer area.

\section{Engineering Department of CINVESTAV}

This system allows increasing the accessibility to the information of the microbial collection in an updated way and with quality assurance, to provide a series of services in an environment of interoperability, 
which allows sharing the resources between the community and microbiology studies. This has allowed at the Collection to be integrated into the information node of the World Biodiversity Information Network in CONABIO (http://www.conabio.gob.mx/ remib/doctos/remib esp.html), who mission is to disseminate the biodiversity of microorganisms, a fact that has had a relevant impact on various sectors in Mexico and Latin America. Collection shares biological information through nodes associated with research centers that house the main scientific collection, decentralized in more than 146 countries. The collection is also a member of the information network of the Strain info.net Bioportal of the University of Ghent, Belgium (http://www.straininfo.net/), with the same objectives of disseminating the biodiversity of microorganisms and a relevant impact on various sectors in the world.

Due to the great development that microbiology has had in recent years to support the progress of biotechnology, the role played by the Microorganism Collection of CINVESTAV is fundamental as a safe guard of biological materials, after having faced different challenges in its history.

It is necessary to strengthen the collaboration channels and communication between professionals in different areas, not only through seminars, symposia and workshops, but also through networks of scientific Exchange on an individual or institutional level in a more effective way, so that researchers can actively participate in initiatives and collaborate with their colleagues from the same or related disciplines, in order to reduce gaps in knowledge and related technologies between microbiologists from developed and non-developed countries. Legal and biosafety aspects related to the acquisition, use and transfer of biological material between collections or institutions, with in the country or in different countries, need to be shaped by the consolidation and unification of criteria.

\section{Acknowledgments}

None.

\section{Conflicts of interest}

Authors declare no conflict of interest exists.

\section{References}

1. OECD. Best practice guidelines for biological resource centres. 2007.

2. OECD Best practice guidelines on biosecurity for BRCs In: best practice guidelines for biological resource. 2007.

3. Sly L. Maintenance and preservation of microbial cultures in a laboratory culture collection. technical note. 1992;14:1-16.

4. World data center for micro organisms (WDCM). the culture collection in this world: WDCM Statistics. 2002

5. World federation collection culture (WFCC). information documenton access to exsitu microbial genetic resources with in the frame work of the conventionon biological diversity. biodiversity committee. Printed by the tropical data base and made available online by the world data center for microorganisms. 1999. 